\title{
O status morfoprosódico dos sufixos -inho/-zinho, -mente e -íssimo no português brasileiro*
}

\section{The morphoprosodic status of the suffuxes -inho/-zinho, -mente and -íssimo in Brazilian Portuguese}

\author{
Camila Witt Ulrich \\ (Universidade Federal do Rio Grande do Sul, Porto Alegre, \\ Rio Grande do Sul, Brasil \\ CNPq, Brasília, Distrito Federal, Brasil) \\ Luiz Carlos Schwindt \\ (Universidade Federal do Rio Grande do Sul, Porto Alegre, \\ Rio Grande do Sul, Brasil \\ CNPq, Brasília, Distrito Federal, Brasil)
}

\section{RESUMO}

Este texto trata da formação morfológica e prosódica de estruturas afixadas do português brasileiro, em especial daquelas formadas por -inho/-zinho, -mente e -issimo, já que esses afixos parecem apresentar uma certa independência em relação a alguns processos da língua, como a neutralização das vogais pretônicas. Assumimos que, em geral, os afixos do português unem-se, no plano morfológico, à raiz, e, no plano prosódico, a outras sílabas átonas. Os sufixos -inho/-zinho, -mente e -íssimo, contudo, dão indícios de uma anexação mais tardia na gramática, isto é, ao radical ou tema e à palavra prosódica.

Palavras-chave: Sufixação. Radical. Acento. Palavra prosódica.

\footnotetext{
* Agradecemos aos pareceristas e revisores pelas sugestões e comentários e ao CNPq pela concessão da bolsa de doutorado vigente da aluna Camila Witt Ulrich. 


\begin{abstract}
This paper discusses the morphological and prosodic formation of affixed structures of Brazilian Portuguese, in special those formed by -inho/-zinho, -mente and -issimo, since these affixes seem to present a certain independency in relation to some processes of the language, as pretonic mid-vowels neutralization. We assume that, in general, the Portuguese affixes are joined, in the morphological level, to the root, and, in the prosodic level, to other unstressed syllables. The suffixes -inho/-zinho, -mente and-issimo, however, provide evidence for a later attachment in grammar, it means, to the stem and to the prosodic word.
\end{abstract}

Key words: Suffixation. Stem. Stress. Prosodic word.

\title{
1. Introdução
}

Este artigo apresenta em linhas gerais uma discussão sobre o tema palavra, a partir de um exercício teórico-experimental. Apesar de parecer uma questão trivial, a definição de palavra vem alimentando discussões há muito tempo em diferentes perspectivas da teoria linguística. Tal complexidade se deve ao fato de se tratar de um termo que se define diferentemente a depender do módulo ou componente da gramática a partir do qual é observado.

Para o componente morfológico, uma palavra é uma unidade portadora de uma raiz ou, ainda, é o elemento que serve de base para processos flexionais e, consequentemente, configura-se como um nó terminal de uma frase - o que lhe confere o rótulo de palavra morfossintática. Já para o componente fonológico, uma palavra é uma unidade formada por sílabas e pés, que apresenta, na visão de diversos autores, maximamente um acento primário. ${ }^{1}$

Muitas formações da língua apresentam isomorfismo entre unidades morfológicas e prosódicas. O foco deste estudo, entretanto, está em estruturas que não exibem perfeito pareamento entre essas unidades - mais especificamente, em estruturas que exibem elementos morfologicamente dependentes que parecem ter alguma autonomia em relação à pauta acentual.

Como reflexo do comportamento distinto destas estruturas para a arquitetura da gramática, tomamos como ponto de partida a ideia de que há um domínio morfológico e um domínio prosódico que devem ser considerados no que diz respeito à anexação de estruturas linguísticas (cf.: Schwindt 2013b). O domínio da afixação morfológica, então, pode ser a raiz (ex. cas- + -eiro) ou o

1. Ainda podemos falar em palavra lexical (ou lexema), se olharmos do lugar do significado, ou em palavra gráfica, numa perspectiva de uso culturalmente inserido de língua. 
radical/palavra ${ }^{2}$ (ex. casa + -eiro); o domínio da anexação prosódica pode ser um conjunto de sílabas/pés (ex. (cas.) + ei.ro.) ou uma palavra prosódica (ex. ('ca.sa.) + ei.ro.).

Com a finalidade de alimentar a discussão sobre a relação entre palavra prosódica e palavra morfossintática em português brasileiro $(\mathrm{PB})$, pretendemos analisar o comportamento de quatro sufixos específicos, a saber, -inho/-zinho ${ }^{3}$, -mente e -íssimo, já que eles apresentam um padrão peculiar em relação a alguns processos do domínio da palavra morfológica e da palavra prosódica.

O objetivo deste artigo, portanto, é discutir e investigar quais são os domínios de anexação desses quatro sufixos.

Assumimos inicialmente as seguintes hipóteses presentes na literatura:

(i) -inho e -zinho são alomorfes de um mesmo morfema (cf.: Bisol 2010) - considerando-se suas peculiaridades distribucionais -, e, juntamente com -mente e -íssimo, se relacionam, no plano mórfico, a radicais; os demais sufixos da língua ligam-se a raízes (cf.: Schwindt 2008, 2013b);

(ii) o fato de existir uma fronteira prosódica entre esses afixos e as bases com as quais se relacionam, o que as protege do fenômeno de neutralização, é evidência a favor da classificação desses elementos como palavras prosódicas independentes.

A investigação que empreendemos e que aqui relatamos visa a corroborar essas hipóteses da literatura, sem que haja compromisso com alguma teoria específica, e a reunir evidências adicionais para tais afirmações.

$\mathrm{O}$ artigo está dividido em duas grandes seções. A primeira concerne à discussão sobre o domínio morfológico dos sufixos do PB e apresenta o comportamento dos quatro sufixos investigados em relação a características derivacionais/composicionais e a processos morfofonológicos que acontecem nos níveis da raiz, do radical ou da palavra. Na segunda parte, tratamos do domínio prosódico dessas mesmas unidades, apresentando resultados de um experimento de análise de fala aplicado a cinco informantes do sexo masculino, elaborado com o objetivo de somar evidência empírica à hipótese prosódica defendida. Assumindo a tese de que cada palavra prosódica possui um único acento primário, observamos a caracterização de informações acústicas relativas

2. Chamamos de radical a base que precede a derivação morfológica, nos termos de Câmara Jr. (1970), ainda que essa estrutura coincida, no mais das vezes, com uma palavra morfológica ou com um tema - este último termo reservado pelo autor para designar a base que precede a flexão. O termo stem, em que se funda essa classificação, não distingue entre radicais derivacionais ou temas flexionais, haja vista que o inglês, diferentemente do português, não se caracteriza pela exigência de que as palavras sejam fechadas por vogais. Nessa língua, ao contrário, raízes, temas (radicais) ou palavras em geral têm forma coincidente.

3. Neste texto, sempre que conveniente, nos referimos às manifestações do diminutivo com o par -inho/-zinho, assumindo a hipótese de se tratar de um mesmo morfema, que pode se realizar sob duas formas na superfície da língua. 
à manifestação do acento em palavras simples e derivadas da língua. Por fim, resumimos as principais conclusões alcançadas com este estudo.

\section{O status morfológico dos sufixos -inho/-zinho, -mente e -íssimo}

Nesta seção, discutimos o comportamento geral dos sufixos do PB com relação à base do processo de derivação morfológica, se a raiz ou o radical. Ao longo da seção, mostramos que, do ponto de vista morfológico, os sufixos -inho/-zinho, -mente e -issimo parecem apresentar comportamento distinto dos demais afixos do PB, já que são mais produtivos, possuem maior independência sintático-semântica e são mais periféricos. Além disso, não se submetem a processos morfofonológicos que ocorrem apenas no nível da raiz, como a assibilação e o abrandamento velar - fenômenos motivados pela vogal /i/ do ambiente derivado. ${ }^{4}$

\subsection{Raiz como base geral da sufixação em português}

Independente da teoria adotada para formalizar o processo de derivação sufixal de uma língua, será necessário se definir a base para esse processo. A pergunta que se formula, do ponto de vista mórfico, é: as palavras derivadas são formadas a partir da união do sufixo a uma raiz ou a um radical (raiz + vogal terminal)?

De partida, algumas considerações precisam ser feitas. Se admitirmos que toda a afixação do PB, em geral, acontece no nível da palavra morfológica ou do radical acrescido da vogal temática (cf.: Scalise 1984, para o italiano; BermúdezOtero 2006, para o espanhol; Matzenauer; Bisol 2016, para o português brasileiro), precisaremos contar com uma regra de apagamento de vogal temática para a maior parte das palavras sufixadas, já que, nessa abordagem, "formativos de radicais nominais de fato ocorrem dentro dos sufixos derivacionais baseados no radical" (Bermúdez-Otero 2006:23). ${ }^{5}$

Por outro lado, se admitirmos que a afixação do PB se dá predominantemente no nível da raiz (cf.: Harris 1983, para o espanhol; Pepperkamp 1997, para o italiano; Alcântara 2010, para o português brasileiro, bem como Rio-Torto 2000, para o português europeu), essa regra não precisará ser aplicada a boa parte dos dados, visto que a maior parte das raízes do PB termina em consoante

4. Apesar de os fenômenos de assibilação e abrandamento modificarem aspectos fonológicos do vocábulo, eles estão intimamente ligados à morfologia, visto que são aplicados apenas em formas derivadas cujo afixo é iniciado pela vogal /i/.

5. Trecho original: "nominal stem formatives do in fact occur inside stem-based derivational suffixes" (Bermúdez-Otero 2006:23). 
(ex. cas-, para casa) e a maior parte dos sufixos nominais é iniciada por vogal (ex. -eiro, em caseiro).

Em pesquisa experimental com palavras derivadas por -al e por -oso ${ }^{6}$ no dicionário Aurélio Eletrônico versão 7.0, conforme relatado em Schwindt (2013b:23-25), encontraram-se apenas 6,5\% e 5,1\%, respectivamente, de dados com uma vogal interveniente entre a raiz e o sufixo (ex. sexúal, monstrúoso). A maior parte dos dados mostra uma relação direta entre a raiz e o afixo derivacional, não havendo justificativa para uma análise generalizada de morfologia baseada no nível da palavra ou do radical com posterior apagamento da vogal terminal no PB.

Além disso, se fosse o radical/palavra a base de toda a derivação morfológica, seria bem motivada a aplicação dessa regra de síncope da vogal também em contextos de hiato entre vogal da base e do sufixo, como se vê em (1). Ao contrário, o hiato se mantém e nenhum processo reparador, como uma epêntese consonantal, por exemplo, é chamado para lidar com a suposta máformação.

$\begin{array}{lll}\text { (1) herói } & \text { hero-í-na } & * \text { heroiCina } \\ \text { canoa } & \text { cano-ei-ro } & * \text { canoaCeiro } \\ \text { óleo } & \text { ole-o-so } & \text { *oleoCoso }\end{array}$

As formações acima listadas mostram que a afixação morfológica parece inclusive preferir estruturas mais marcadas (o hiato, nesse caso) a produzir formações a partir do radical/palavra morfológica, o que contribui para nossa convicção em estabelecer a raiz como base da derivação com sufixos ordinários do português.

\subsection{Sufixos baseados no radical}

Os sufixos investigados neste estudo, -inho/-zinho, -mente e -íssimo, contrariamente à tese que acabamos de defender para os sufixos do sistema de modo geral, apresentam características que sugerem sua anexação excepcional a radicais/palavras, e não a raízes. Esses sufixos são mais produtivos do que os demais sufixos, mais independentes sintático-semanticamente e assumem posição mais periférica na constituição das palavras.

A regra que forma palavras com esses quatro elementos apresenta índices de produtividade (nos sentidos de disponibilidade e rentabilidade - termos propostos por Corbin 1987) muito superiores aos das regras que envolvem

6. O referido estudo experimental foi realizado no ano de 2012 e contou com a colaboração das estudantes de graduação Camila Witt Ulrich e Thiely Andressa Schwingel, tendo seus resultados apresentados no XXIV Salão de Iniciação Científica. De todos os sufixos do PB, centramos em -al e -oso, por serem os mais vulneráveis na língua à interveniência de uma vogal, separando-os da raiz. Esse fenômeno raramente atinge outros sufixos em português. 
os demais sufixos. Essas formações apresentam grande vitalidade e possuem poucas restrições de uso. Uma evidência disso está em usos novos, cada vez mais recorrentes na língua, em que se empregam formas de diminutivo e de superlativo a bases não nominais, como em correndinho ou correndíssimo.

Os afixos investigados parecem mostrar algum tipo de independência sintática e/ou semântica não encontrada em outras formações sufixais. $\mathrm{O}$ sufixo -mente, por exemplo, assim como alguns prefixos também relativamente independentes, pode ser omitido se repetido em uma estrutura coordenada (ex. formal ou informalmente). O sufixo -zinho, em alguns contextos, pode também figurar como forma "livre" da língua, no sentido de que pode ocorrer isoladamente, como em era só um zinho falando = algunzinho, pessoazinha (cf.: Schwindt 2014) ${ }^{7}$

Por fim, como dissemos, os sufixos em foco são mais periféricos em relação a todos os demais sufixos derivacionais da língua, antepondo-se apenas, quando palavras variáveis da língua, a sufixos flexionais. É o caso da relação entre -oso ou -(i)dade e -(z)inho: monstro / monstrinho / monstruoso / monstruosidade / monstruosinho / monstruosidadezinha.

Em muitas das teorias que explicam a arquitetura da gramática, podemos diferenciar elementos como mais internos ou mais externos à base no momento de formação da palavra. Como argumento adicional ao comportamento puramente morfológico que acabamos de exemplificar, podem-se citar alguns processos morfofonológicos que atuam como evidência do domínio gramatical da afixação. Lee (1995), inserido em uma perspectiva que prevê um léxico organizado em níveis - a Fonologia e Morfologia Lexical (LPM) -, classifica os sufixos do PB em dois níveis. Segundo o autor, o nível ao qual cada sufixo pertence pode ser reconhecido a partir do seu comportamento em relação a regras morfofonológicas da língua. ${ }^{8}$

Os sufixos de nível I estão em maioria na língua, ligam-se à raiz - são, portanto, mais internos na estruturação morfológica - e sofrem regras como a assibilação e o abrandamento velar, que ocorrem apenas em ambientes derivados em que há uma vogal alta /i/ como segmento inicial do sufixo.

7. Parece-nos que -inho não apresenta grande probabilidade de aparecer isoladamente, mas, por julgarmos que ambas as realizações pertencem ao mesmo morfema, imaginamos que a consoante seja chamada para estes casos por preferências fonotáticas. Também o sufixo -íssimo, nesse ponto de vista, não possui a mesma independência de -(z)inho e -mente, possivelmente por formar adjetivos e não substantivos. Registramos de oitiva, porém, um curioso dado nesse sentido: você está cansado? eu? issimo!.

8. Essa análise é passível de formalização em outros modelos, para além da LPM. Na Teoria da Otimidade, por exemplo, restrições de alinhamento podem dar conta de nivelamento de afixos (cf.: Schwindt 2008); na Morfologia Distribuída, uma alternativa é se inserirem esses afixos em nós mais externos em relação aos dos demais sufixos. 
(2) Sufixos-ia/-idade/-iça

$\begin{array}{lll}\text { assibilação } & \text { base } & \text { derivação } \\ \text { abrandamento velar } & \text { pacien } / \mathrm{t} / \mathrm{e} & \text { paciên } / \mathrm{s} / \mathrm{ia} \\ & \text { elétri } / \mathrm{k} / \mathrm{o} & \text { eletri } / \mathrm{s} / \mathrm{idade}\end{array}$

Os sufixos que não se submetem a esses processos e, por esse motivo, recebem acento de forma independente no nível I - onde, para Lee (1995), está situada a regra de acentuação -, podem ser classificados como sufixos do nível II.

(3) Sufixos -inho/-issimo

$\begin{array}{lll} & \text { base } & \text { derivação } \\ \text { assibilação } & \text { pacien/t/e } & \text { pacien/t/inho } \\ \text { abrandamento velar } & \text { elétri/k/o } & \text { eletri/k/inho }\end{array}$

Nessa perspectiva, os afixos que exploramos aqui pertenceriam ao nível II do léxico ou, em termos menos comprometidos teoricamente, a níveis ou posições mais externas na formação de palavras em PB.

Considerando-se a tese de que, no $\mathrm{PB}$, os sufixos adjungem-se à raiz, e não à palavra, temos de admitir, então, que os sufixos -inho/-zinho, -mente e -íssimo são diferentes dos demais ao se unirem a uma base morfológica já estruturada, um radical ou uma palavra morfológica.

Apesar de termos tratado até aqui -inho e -zinho como opções de realização de um mesmo morfema, há quem defenda que são sufixos distintos e que, por consequência, -inho seria implementado em uma posição mais interna (nível I), enquanto -zinho seria mais externo (nível II) - hipótese que, entendemos, descaracteriza o caráter epentético da consoante /z/.

A fim de verificar se essas duas estruturas possuem escopos lexicais diferentes ou não, Ulrich e Schwindt (2012) analisaram a aplicação desses afixos em palavras simples e compostas (ex. mercado e supermercado) para atestarem se produtos de composição morfológica restringem-se à formação com -zinho, evitando formações com -inho (i.e., supermercadozinho em vez de supermercadinho). $\mathrm{O}$ experimento foi dividido em duas partes equivalentes ${ }^{9} \mathrm{e}$ cada uma das partes foi aplicada a 10 informantes. $\mathrm{Na}$ execução da tarefa, os informantes liam uma frase com a palavra-alvo (ex. supermercado) na tela do computador e deviam transformar a estrutura em uma forma diminutiva. Foram testadas, alternadamente, 10 palavras simples e 10 palavras compostas.

9. Cada uma das aplicações do teste apresentava 5 palavras simples e 5 palavras compostas com bases distintas. Por esse motivo, nenhum informante teve de produzir a forma diminutiva para a palavra simples e também para sua palavra composta respectiva (ex. avô e tio-avô). 
Em palavras simples, foi predominante o emprego de -inho em palavras paroxítonas (ex. amigo); já em palavras compostas, houve alternância na escolha entre -inho e -zinho, ainda prevalecendo o uso de -inho. Essa alternância nos sugere que, em relação às formações compostas, não parece haver alguma barreira morfossintática que determine de modo mais contundente ou definitivo a seleção de uma ou de outra forma deste sufixo; -inho e -zinho assumem o mesmo comportamento, confirmando a ideia de que são alomorfes de um mesmo morfema.

Esses dados parecem corroborar a asserção de Bisol (2011:82), que afirma que "a base do afixo DIM é a palavra morfológica, definida em termos de radical + vogal temática, doravante VT, em nominais temáticos, casa, bolo, parede, ou somente radical em nominais atemáticos, café, mal, pomar".

\section{O status prosódico dos sufixos -inho/-zinho, -mente e -íssimo}

Nesta seção, discutimos o comportamento fonológico ou prosódico ${ }^{10}$ das palavras afixadas por -inho/-zinho, -mente e -íssimo.

Partimos do pressuposto de que a união de duas estruturas prosódicas pode se dar por composição prosódica ${ }^{11}(\mathrm{PWd}+\mathrm{PWd})$, adjunção prosódica ( $\mathrm{PWd}+$ sílaba) ou incorporação prosódica (sílaba + sílaba).

Quadro 1 - Tipos de formações prosódicas, conforme Schwindt (2013b)
i. incorporação
ii. adjunção
PWd
$\mathrm{PWd}$
iii. composição
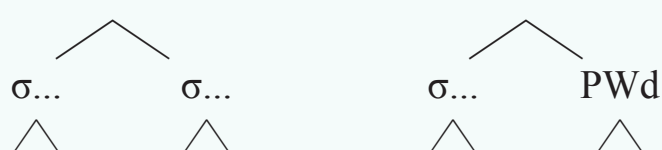
$\overbrace{\text { afixo }}^{\text {PWd }} \overbrace{\text { base }}^{\text {PWd }}$
$\triangle_{\text {afixo }} \triangle_{\text {base }}$
$\triangle_{\text {afixo }} \triangle_{\text {base }}$

Essa proposta opera com dois constituintes básicos da Escala Prosódica (Selkirk 1982, Nespor; Vogel 1986): a sílaba e a palavra prosódica. No caso da incorporação, há a união de sílabas que, em conjunto, formam um ou mais pés métricos e uma só palavra fonológica. Já no processo de adjunção, sílabas se unem para formarem, com uma palavra já existente, uma palavra prosódica

10. Os termos fonológico e prosódico são tomados como sinônimos neste estudo.

11. Assumimos a tese de que composição prosódica não se confunde necessariamente com composição morfológica. Na composição prosódica, não está em jogo a existência de duas ou mais raízes como na composição morfológica. Também a noção de composição semântica ou lexical, apesar de ensejar isomorfismo com a noção de composição morfológica, nem sempre estabelece essa correspondência de forma plena. Assim, em uma palavra como sobrepor, podemos ter 2 palavras fonológicas ( 2 acentos), 1 palavra morfológica (1 só raiz) e 2 entidades ou palavras lexicais ( 2 significados que se estabelecem com relativa independência). Isso se expressa convenientemente em restrições de alinhamento generalizado (cf.: Schwindt 2014). 
maior. Por fim, na composição prosódica, duas palavras prosódicas são unidas e formam uma unidade superior à palavra e inferior à frase fonológica.

Acreditamos (cf.: Schwindt 2013b) que os elementos sufixais do PB, em geral, são unidos à base em um processo de incorporação prosódica, já que essa base ainda não possui acento primário atribuído. O reconhecimento do tipo de formação prosódica da estrutura derivada se dá a partir de processos que ali se aplicam ou deixam de se aplicar. Como exemplos de regras que acontecem no nível da palavra prosódica, citamos os casos do quadro abaixo.

Quadro 2 - Processos fonológicos do domínio da palavra

\begin{tabular}{|c|c|}
\hline Processo & Exemplo \\
\hline i) neutralização da vogal média pretônica & $\mathrm{b} / \varepsilon / \mathrm{lo}-\mathrm{b} / \mathrm{e} / \mathrm{leza}$ \\
\hline ii) redução da vogal átona final & $\operatorname{bol}[\mathrm{o}] \sim \operatorname{bol}[\mathrm{v}]$ \\
\hline iii) vozeamento do $/ \mathrm{s} /$ intervocálico & ga[z]ozo $(*$ ga[s]oso $)$ \\
\hline $\begin{array}{l}\text { iv) ressilabação com superficialização da nasal } \\
\text { em onset }\end{array}$ & bon.zi.nho $(*$ bo.[ni]nho) \\
\hline v) nasalização variável da vogal precedente & p[ã]nela (*cap[ã] nova) \\
\hline
\end{tabular}

Se estes processos nos dão indícios dos limites de uma palavra prosódica, imaginamos que a sufixação, por se caracterizar como um processo de incorporação prosódica à base, deva resultar em uma estrutura constituída de um único acento, ou seja, uma única palavra prosódica.

O que acontece, porém, é que os quatro sufixos investigados (-inho/-zinho, -mente e -íssimo) apresentam comportamento distinto dos demais sufixos em relação a alguns dos processos mencionados. Em relação à neutralização, que acarreta uma redução do inventário vocálico em alguns dialetos do PB como veremos detalhadamente na próxima seção -, as vogais médias-baixas das bases conservam sua altura mesmo após a derivação, ao contrário do que acontece quando da associação a outros sufixos (ex. b[e]leza, mas $b[\varepsilon] l i n h o$ ). Há também redução da vogal átona final nos dois casos investigados iniciados por consoantes, -zinho e -mente (ex. bel[v]zinho, fort [I]mente). Ainda, como vimos na seção 2.2 , eles não se submetem à assibilação e ao abrandamento velar.

Constatamos, portanto, que, prosodicamente, os quatro sufixos analisados neste estudo também são diferentes dos demais sufixos. São sufixos composicionais (cf.: Schwindt 2000), já que formam com a base compostos prosódicos. ${ }^{12}$

A ideia que estamos sugerindo para os casos de -inho/-zinho, -mente e -íssimo vai além da ideia de atração do acento, que acontece com muitos dos sufixos do PB. Além de portarem o acento principal da palavra, consideramos

12. Esse mesmo caráter independente é admitido para prefixos que apresentam comportamento distinto dos demais frente a outros processos da língua (ex. pré-, em pré-escola), chamados prefixos composicionais por Schwindt (2000). 
que esses afixos, por apresentarem comportamento de palavra prosódica independente, mantêm um acento primário na palavra-base. Se entre as bases e esses afixos parece haver uma barreira para processos fonológicos do nível da palavra, podemos sustentar que, fonologicamente, eles podem ser tratados como palavras prosódicas independentes.

\subsection{A neutralização das vogais pretônicas}

Como principal argumento para esta abordagem, que trata os quatro sufixos como elementos composicionais prosodicamente, tomamos como base o fenômeno fonológico de neutralização das vogais pretônicas, que anula a distintividade entre as vogais médias-baixas e médias-altas nesta posição.

De acordo com Câmara Jr. (1975), temos sete fonemas vocálicos no inventário do português brasileiro.

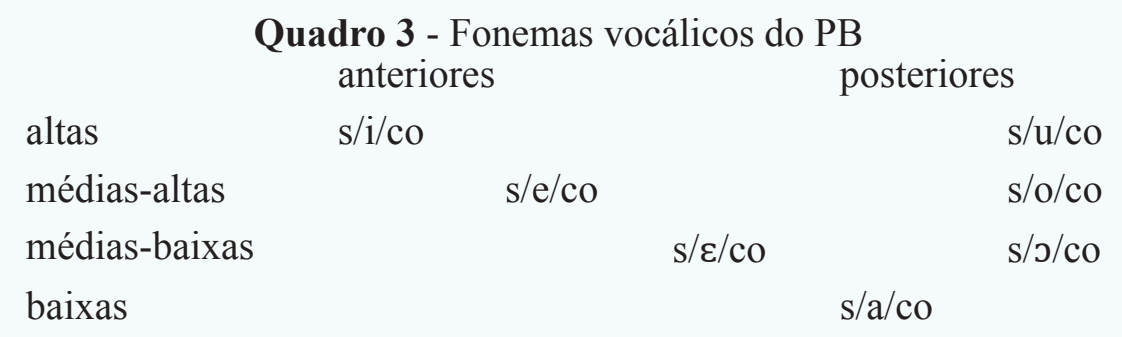

Essas sete vogais estão presentes de forma distintiva apenas na pauta tônica, posição apresentada no quadro acima. As posições átonas sofrem algumas simplificações no sistema que, em alguns casos, resultam em reduções no inventário.

A simplificação do sistema a que nos referimos acima chama-se neutralização. Anoção de neutralização foi amplamente discutida por Trubetzkoy (1969 [1939]) ao tratar do conceito de arquifonema. Para o autor, neutralização é a perda de distintividade entre dois segmentos em uma determinada posição. Dois segmentos até então contrastivos, capazes de diferenciar significados (ex. $c[o] r t e-c[j] r t e)$, passam a não ter mais essa função.

De modo simplificado, seguindo Trubeztkoy, podemos dizer que entre os caminhos para se lidar com a neutralização estão a coexistência das formas em competição, a convergência para uma dessas formas ou, ainda, o emprego de uma terceira forma, que não coincide completamente do ponto de vista fonético com nenhuma das concorrentes (cf.: Schwindt 2013a). No caso da neutralização da pretônica em PB, em muitos dialetos, parece que estamos sujeitos ao primeiro tratamento, isto é, convivemos com duas realizações (duas pronúncias possíveis) para essa posição acentual, sem que haja mudança no significado do vocábulo (ex. c[o]ração e c[j]ração). Noutros tantos dialetos, em especial no sul e sudeste do país, estamos sujeitos ao segundo tratamento, ou 
seja, optamos de forma mais ou menos categórica pelas vogais médias-fechadas /e, o/, restringindo o emprego de médias-baixas tão somente à posição tônica da palavra. ${ }^{13}$
(4)$$
\mathrm{b} / \mathrm{\varepsilon} / \mathrm{lo} \quad \mathrm{b} / \mathrm{e} / \mathrm{leza}
$$$$
\mathrm{b} / \mathrm{s} / \mathrm{la} \quad \mathrm{b} / \mathrm{o} / \mathrm{lada}
$$

Nestes dialetos, contudo, em que se constata redução do inventário no contexto de neutralização, esse alteamento da vogal falha restritamente quando da associação à base dos quatro sufixos investigados, ou seja, a vogal médiabaixa da base se preserva, categoricamente, mesmo após o aumento de sílabas à direita da palavra.

$\begin{array}{lll}\mathrm{b} / \mathrm{\varepsilon} / \mathrm{lo} & \mathrm{b} / \mathrm{c} / \mathrm{lamente} & \mathrm{b} / \mathrm{\varepsilon} / \text { líssimo } \\ \mathrm{b} / \mathrm{J} / \mathrm{la} & \mathrm{b} / \mathrm{s} / \mathrm{linha} & \mathrm{b} / \mathrm{J} / \mathrm{lazinha}\end{array}$

Sabendo-se que o PB aloca o acento primário em uma janela de três silabas a partir da borda direita da palavra (cf.: Bisol 1992), e estando vogais médias-baixas, nesses sistemas, restritas a posições tônicas, sustentamos que há evidências para tratar as formações com os sufixos investigados como estruturas formadas por duas palavras prosódicas (cf.: Schwindt 2013a).

Além disso, o fenômeno de neutralização apresentado acima ocorre diante dos afixos em questão também em outras línguas. No português europeu (PE), podemos considerar que -zinho e -mente são palavras prosódicas, já que permitem que a sílaba acentuada da base não sofra nenhum tipo de redução, ao passo que sílabas átonas finais sofrem redução regularmente.
(6) $\mathrm{g}[\mathrm{o}] \mathrm{lo}$
gol[u]zinho
$*_{\mathrm{g}}[\mathrm{u}]$ luzinho
al[ $[\varepsilon] g r e$
al $[\varepsilon]$ gremente
*al[e]gremente

Os dados com -inho, por outro lado, parecem apresentar comportamento distinto dos encontrados para o PB (ex. g[u]linho, conforme Villalva 1992). ${ }^{14}$

O espanhol, apesar de não apresentar vogais médias-baixas, apresenta um processo de comportamento similar ao de neutralização das pretônicas. $\mathrm{Na}$ posição tônica, em contextos em que o PB apresenta vogais médias-baixas, o espanhol pode apresentar ditongos (ex. p[J]rta $\sim p[\omega e] r t a$ ). Quando há um processo de sufixação, este ditongo passa a ser uma única vogal plena (ex. $s[j e ́] n t e-s[e] n t i ́ m o s, m$ [Фé]rte - $m$ [o]rtál). Porém, esse processo não acontece com afixos que, em uma versão análoga à nossa hipótese para o $\mathrm{PB}$, seriam considerados palavras prosódicas (ex. b[je]xo - b[je]xísimo).

13. Schwindt (2013a:142) sugere que o último tratamento, este que resulta no emprego de uma terceira forma que não as formas concorrentes, é o que possivelmente dá conta da neutralização das átonas finais (ex. /e/ $\sim / \mathrm{i} / \rightarrow[\mathrm{I}]$, em leit[I]; /o/ $/ \mathrm{u} / \rightarrow[\mathrm{U}]$, em ov[U]).

14. Esses casos comparativos entre PB e PE, portanto, merecem atenção especial e poderão ser abordados em perspectivas futuras. 
Já o italiano apresenta o mesmo inventário fonológico do PB para a posição tônica, com sete vogais distintivas, e, nas posições pretônicas, não apresenta vogais médias-baixas $/ \varepsilon, \mathrm{J} /$, assim como o dialeto do sul do Brasil. Há casos de palavras compostas que mantêm as vogais médias-baixas nas duas bases e, por isso, muitos autores admitem serem constituídas de duas palavras prosódicas (ex. $t[\varepsilon] r r a-c[$ J $] t t a, p[J] r t a-o m b r[\varepsilon] l l i) .{ }^{15}$

$\mathrm{Se}$, de fato, os quatro sufixos investigados podem ser considerados palavras prosódicas independentes, e sabendo que toda palavra prosódica possui maximamente um acento primário, partimos para uma investigação empírica acerca das manifestações do acento primário nestas formações. A questão norteadora que guia a elaboração e a análise desta etapa da pesquisa é: há evidências fonéticas para sustentar a hipótese de que os sufixos -inho/-zinho, -mente e-íssimo são palavras fonológicas independentes no PB?

\subsection{Análise acústica: o comportamento fonético dos sufixos com- posicionais}

Em investigação anterior (cf.: Ulrich 2013), percebemos que, por vezes, os falantes do PB tendem a reconhecer e classificar sílabas com vogais médiasbaixas como mais proeminentes, mesmo quando elas se encontram em posição considerada pretônica (ex. be em belinho). Superando as expectativas, de um total de 50 participantes, 30 identificaram /bo/ como mais proeminente em bolinha e 26 identificaram /s $1 /$ como mais proeminente em solzinho. Essa constatação motivou nosso interesse pela busca de informações de natureza fonética.

Gráfico 1 - Identificação de sílabas tônicas em bolinha e solzinho (cf.: Ulrich 2013)
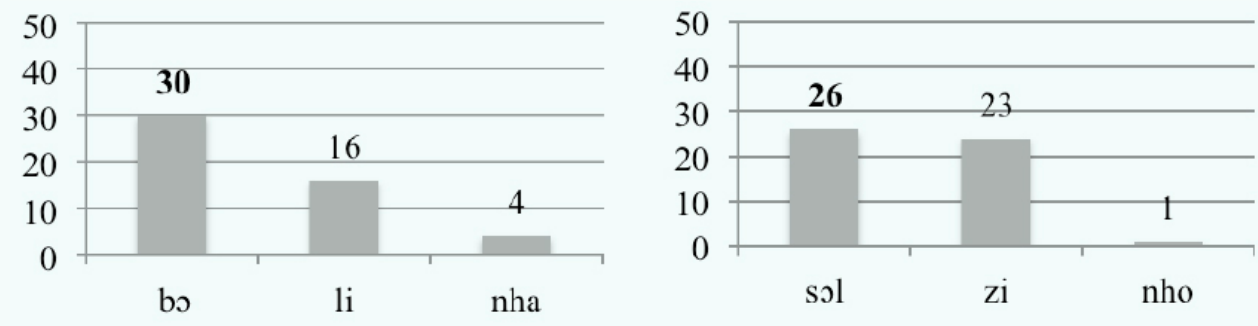

A fim de compreendermos se há, de fato, razões fonéticas que mostrem que tais sílabas são mais proeminentes às demais, investigamos os principais correlatos acústicos do acento primário no $\mathrm{PB}$ e, posteriormente, aplicamos um experimento a cinco informantes.

Em geral, o acento não possui um único correlato acústico. Vários fatores podem interagir e atuar como sinalizadores da presença de uma sílaba ou vogal 
predominante em relação às demais sílabas ou vogais da palavra. Alguns desses fatores podem ser, por exemplo, duração, intensidade, F0 e demais frequências dos segmentos vocálicos.

Para o português brasileiro, a duração parece ser o correlato mais confiável para a localização do acento primário. Isso significa dizer que sílabas tônicas tendem a durar mais do que sílabas átonas (cf.: Massini 1991, Cantoni 2013, Barbosa; Madureira 2015). Há também análises que defendem uma interação entre duração e intensidade na posição acentuada ou uma queda mais brusca na sílaba seguinte à sílaba tônica (cf.: Massini 1991, Moraes 1998), ou seja, além de durar mais, a sílaba acentuada tende a apresentar valores de intensidade superiores aos das demais sílabas.

Com o objetivo de investigar se os parâmetros mencionados estão presentes nas sílabas consideradas pretônicas e tônicas de nossos dados, realizamos um estudo de base acústica, o qual resumimos na próxima seção.

\subsubsection{Experimento}

Para nossa investigação acústica, coletamos dados de fala de cinco sujeitos do sexo masculino, de 20 a 30 anos de idade, moradores da região metropolitana de Porto Alegre e, portanto, representativos do dialeto falado no sul do Brasil. ${ }^{16}$

Elaboramos sentenças controladas com o contexto Diga X pra mim, pois, conforme Ladefoged (2005:7), em experimentos com frases-veículo, i) o informante não altera a entonação na pronúncia da sentença (o que geralmente acontece na leitura de uma lista de palavras); ii) a comparação entre duração de sílabas ou palavras se torna mais fácil e mais segura.

No lugar de $X$, inserimos palavras relacionadas ao objeto de nosso estudo: palavras simples sem vogal média-baixa (ex. b/o/lo) e com vogal média-baixa (ex. $b / \varepsilon / l o$ ); palavras complexas com neutralização da vogal pretônica (ex. b/e/ leza) e com vogal média-baixa na posição pretônica (ex. b/E/lamente); palavras compostas sem vogal média-baixa (ex. $d / e / d o-d / u / r o$ ) e com vogal média-baixa (ex. $t / \varepsilon / c o-t / \varepsilon / c o$ ).

Selecionamos 62 palavras para o experimento e cada uma das sentenças foi lida duas vezes por cada um dos cinco informantes, contabilizando um corpus de 620 dados a serem analisados.

As gravações foram feitas com um microfone headset AKG L520 ligado a um gravador digital Zoom $\mathrm{H} 4 \mathrm{~N}$ e os dados sonoros foram analisados acusticamente através do software Praat versão 5.3.84 (Boersma; Weenick 2005). Para averiguar a significância estatística dos resultados obtidos, o teste Wilcoxon foi aplicado através do software R, pacote RStudio versão 0.99.484.

16. Projeto aprovado pela Comissão de Pesquisa em Letras e pelo Comitê de Ética em Pesquisa da UFRGS através da Plataforma Brasil, CAAE 46351815.8.0000.5347. 
Nos dados coletados, medimos os parâmetros duração (ms) e intensidade máxima $(\mathrm{dB})$. A medida de duração que utilizamos na apresentação dos resultados refere-se unicamente à duração relativa, isto é, ao valor que cada sílaba durou em sua respectiva palavra, não importando a velocidade de fala do enunciado (cf.: Brod; Seara 2013).

\subsubsection{Principais resultados}

A seguir, apresentaremos nossos principais resultados, os quais foram divididos em duas seções - uma para tratar da duração das sílabas analisadas e outra para tratar da intensidade dessas mesmas unidades.

\subsubsection{Duração}

Para as palavras simples (ex. belo), encontramos o que a literatura já vem afirmando: as sílabas tônicas duram mais que as átonas (cf.: Barbosa; Madureira 2015).

Para a análise das palavras derivadas, estabelecemos comparações entre palavras de contexto fonético aproximado, como é o caso de belinho e beleza, em que nosso foco estava na análise do sufixo -inho em oposição a outro sufixo da língua.

Gráfico 2 - Duração relativa das sílabas de belinho e beleza

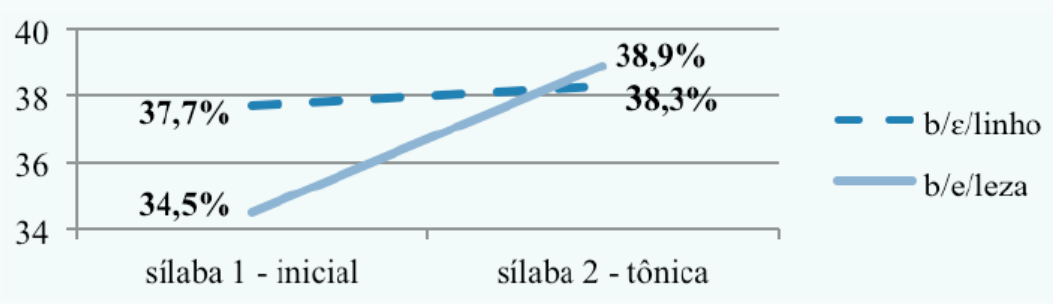

A partir da leitura do gráfico 2, vemos que a sílaba inicial de beleza, palavra que porta um único acento primário, ocupou $34,5 \%$ da palavra, enquanto sua tônica ocupou $38,9 \%$. A diferença entre os valores não foi considerada estatisticamente relevante. Já em belinho, que hipotetizamos ter dois acentos primários em algum momento de sua formação, as sílabas revelaram valores mais próximos e não apresentaram diferença estatística. Se considerarmos que belo já possui um acento, e que ele é mantido por alguns resquícios na base após a anexação de -inho, faz sentido que as duas sílabas apresentem valores próximos.

O mesmo exercício comparativo será agora apresentado para o trio bolada, bolinho e bolinha. 
Gráfico 3 - Duração relativa das sílabas de bolada, bolinho e bolinha

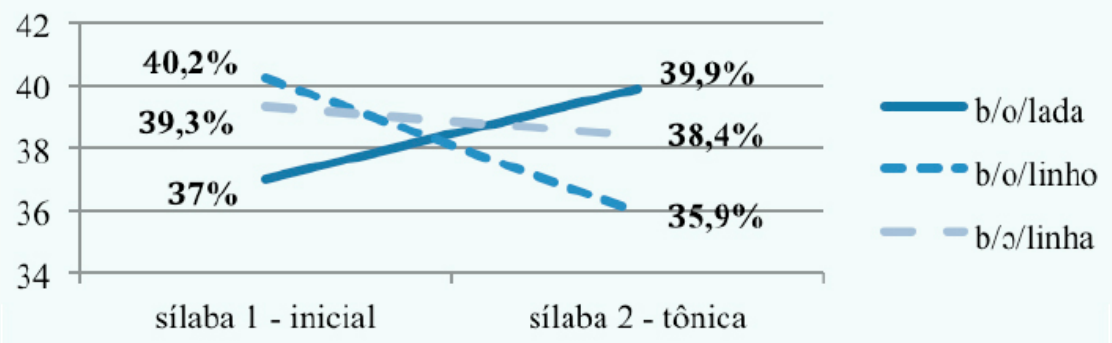

Bolada, dado que apresenta vogal média-alta na pauta pretônica, resultado de neutralização, teve a sílaba inicial mais curta (37\%) e uma sílaba tônica mais alongada (39,9\%). Já o contrário se deu com bolinho e bolinha, que apresentaram sílabas iniciais mais longas do que as sílabas tônicas. Além disso, as sílabas iniciais de palavras com -inho não apresentaram diferença estatística e ambas se opuseram à sílaba inicial bo, de bolada.

Os dados com o sufixo -íssimo mostraram valores próximos entre a sílaba dita pretônica e a sílaba tônica, tanto em início de palavra (ex. novíssimo) ou em meio de palavra (ex. gostosíssimo).

Gráfico 4 - Duração relativa das sílabas de novíssimo

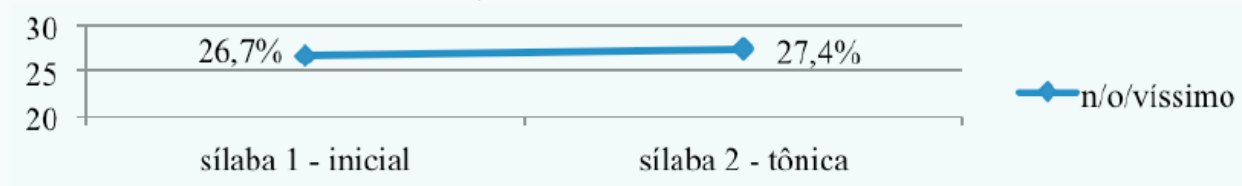

Já os dados com os sufixos -zinho (ex. belozinho) e -mente (ex. belamente) apresentaram o mesmo comportamento prosódico dos compostos morfológicos: maior duração na sílaba principal, como vemos no gráfico 5, mas duas proeminências na sequência total de sílabas, já que a sílaba tônica da palavrabase (ex. bê, em bêbado) exibiu maior duração do que todas as demais átonas.

Gráfico 5 - Duração relativa das sílabas de bebadozinho, petalazinha e rotulozinho

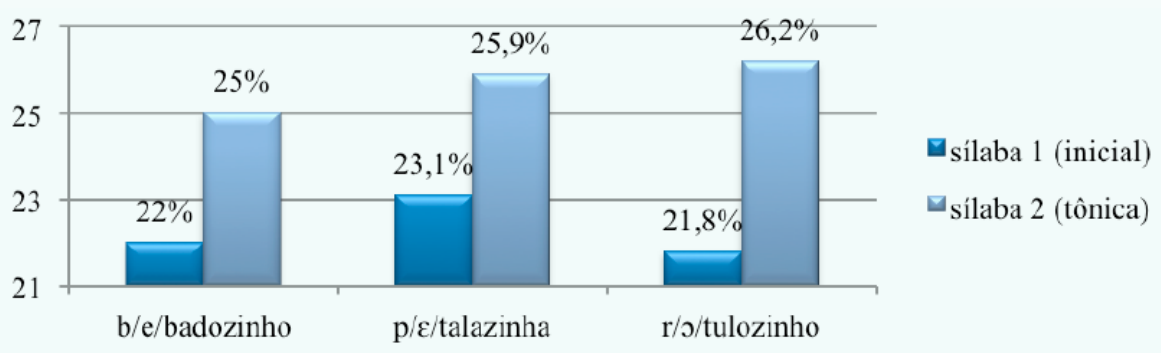

Isto significa dizer que, dentre as átonas, a sílaba que continha o acento da base ainda foi superior às demais sílabas da palavra. 


\subsubsection{Intensidade}

Analisando-se o parâmetro intensidade para as palavras simples, novamente encontramos o que era esperado: as sílabas tônicas mostraram-se mais intensas do que as átonas.

Apresentamos, no gráfico 6, uma comparação que leva em conta a intensidade máxima em dados formados pelo sufixo -inho.

Gráfico 6 - Intensidade máxima das sílabas de noviça, novinho e novinha

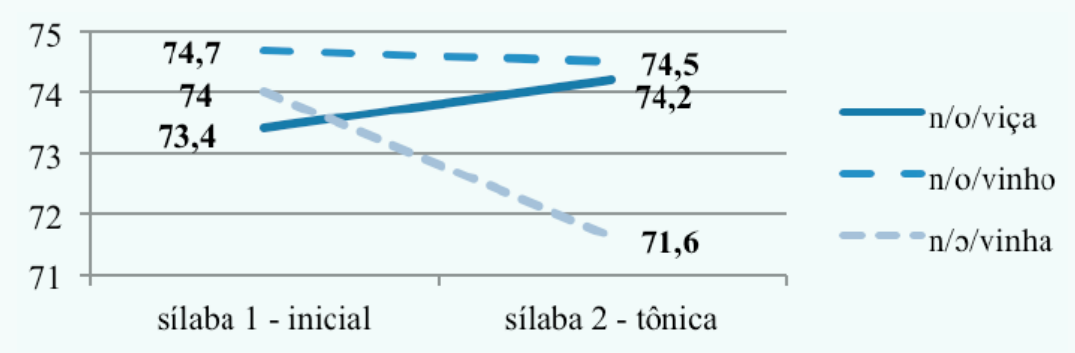

No gráfico acima, vemos que as sílabas iniciais das palavras formadas por -inho (novinho e novinha) tiveram comportamento igual ou superior à sílaba tônica, enquanto noviça, que também possui uma vogal alta na posição tônica e que apresenta um único acento primário, revelou crescimento nos valores de intensidade.

$\mathrm{Na}$ análise dos dados formados por -zinho, os valores de intensidade mais altos foram localizados, em geral, nas sílabas iniciais.

Gráfico 7 - Intensidade máxima das sílabas de bebadozinho, petalazinha e rotulozinho

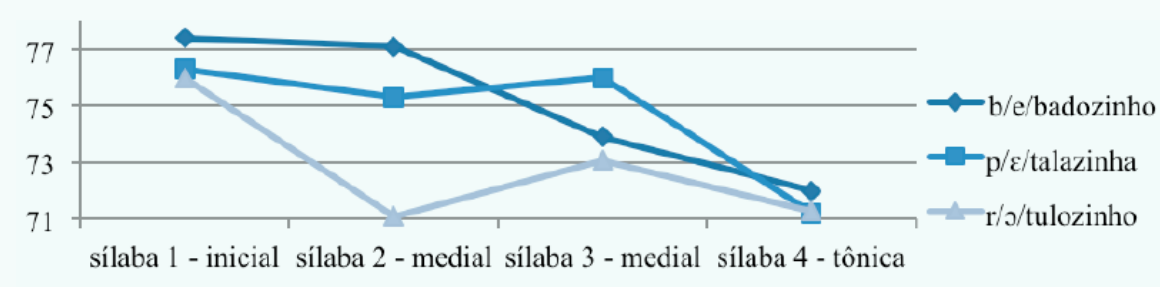

Nos dados formados por -íssimo, encontramos comportamentos variados entre os valores de intensidade de sílabas pretônicas e tônicas. 
Gráfico 8 - Intensidade máxima das sílabas de gostosíssimo e gostosissima

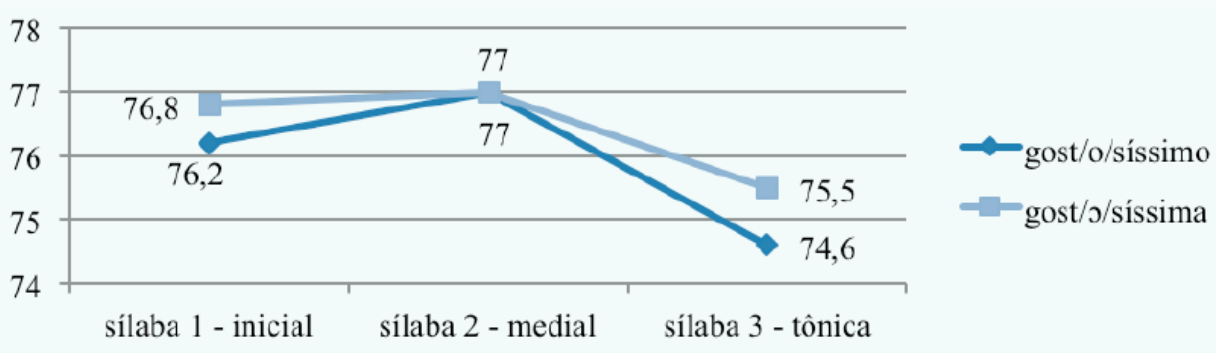

Já nas comparações realizadas para o sufixo -mente, encontramos valores relativamente altos de intensidade na sílaba inicial, a qual obteve crescimento em direção à tônica apenas no caso de novidade, que possui um único acento primário.

Gráfico 9 - Intensidade máxima das sílabas de novidade e novamente

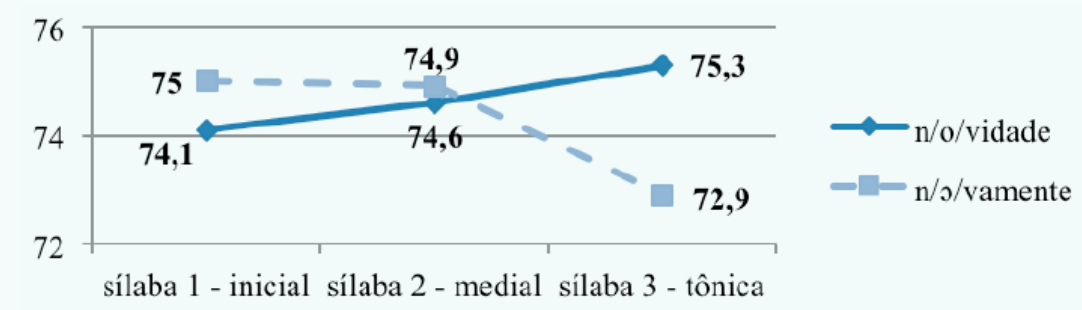

Imaginamos que, já que /men/ já é marcado por uma maior duração, faz algum sentido, nesse caso, que /nJ/ seja marcado por uma maior intensidade. Assim, as duas palavras prosódicas poderiam estar sendo marcadas por parâmetros acústicos distintos.

De forma geral, observamos que muitos dados apresentaram uma taxa de intensidade muito alta na sílaba inicial, independentemente do tamanho da palavra analisada. Esse resultado pode sugerir, então, alguma influência do tipo de experimento desenvolvido, já que os informantes parecem colocar ênfase na sílaba inicial da única palavra que muda na sequência da frase-veículo.

Cruzando os resultados obtidos para os parâmetros duração e intensidade, vemos que, na maior parte dos casos, há maior intensidade na sílaba inicial e maior duração na sílaba tônica. Porém, quando a intensidade maior não estava alocada na sílaba inicial, estava na sílaba tônica; quando a duração maior não estava na tônica, estava na sílaba acentuada da base do processo de derivação.

\section{Considerações finais}

Neste estudo, discutimos o status morfológico e prosódico de sufixos do português brasileiro, de modo especial de quatro sufixos que parecem se comportar como unidades menos dependentes das bases a que se ligam. Nesse âmbito, exploramos o processo de neutralização de vogais médias pretônicas, 
que consideramos um dos principais indicadores dessa autonomia, na perspectiva morfofonológica e acústica.

Com relação ao locus morfológico da afixação no $\mathrm{PB}$, questão ligada à primeira hipótese de trabalho, defendemos que, em geral, os sufixos do PB unem-se à raiz. Os casos especiais da língua comportam as formações com -inho, -zinho, -mente e -íssimo, que não se submetem a processos que acontecem no nível da raiz e, por isso, são unidos diretamente ao radical (ao tema ou à palavra, em outros termos).

Com relação ao locus prosódico, questão ligada à segunda hipótese de trabalho, vimos que, em geral, os sufixos do PB parecem ser anexados à base por um processo de incorporação, que une sílabas átonas para a construção de uma palavra prosódica. Os morfemas -inho/-zinho, -mente e -íssimo, diferentemente, parecem não se submeter a processos que acontecem no nível da palavra prosódica e, por isso, integram estruturas constituídas de duas palavras prosódicas - compostos prosódicos.

Como evidência adicional à tese de independência desses afixos, perguntamos se haveria pistas fonéticas para sustentar a hipótese de que os sufixos -inho/-zinho, -mente e -íssimo são palavras fonológicas no PB. Podemos afirmar que encontramos nos resultados para o parâmetro duração valores expressivos nas sílabas das bases investigadas. Salvaguardada a hipótese de que esses dados estejam influenciados por outros fatores, tais como a duração intrínseca dos segmentos, nossos achados contribuem para corroborar nossas hipóteses mais gerais. Os resultados para o parâmetro intensidade, por outro lado, foram menos informativos, já que muitas produções tiveram a sílaba inicial produzida com maior intensidade. Esse resultado, contudo, não contraria nossa hipótese de trabalho, apesar de ser insuficiente para confirmá-la. Suspeitamos de alguma influência do tipo de instrumento adotado, o que sugere seu refinamento em etapa futura. Um caminho possível é o de se proporem experimentos contendo pseudopalavras formadas por cada um dos sufixos investigados, além de outros formatos de frases. Isso poderia permitir verificar com alguma acuidade a suposta influência da duração intrínseca dos demais segmentos átonos e da posição da palavra dentro do enunciado para os parâmetros analisados.

Recebido em: 07/12/2016

Aprovado em: 07/07/2017

Emails:

Camila Witt Ulrich camilawittulrich@gmail.com Luiz Carlos Schwindt schwindt@ufrgs.br 


\section{Referências}

ALCÂNTARA, Cíntia. 2010. As classes formais do português brasileiro. Letras de Hoje, Porto Alegre, v. 45, n. 1, p. 5-15, jan./mar.

BARBOSA, Plínio Almeida; MADUREIRA, Sandra. 2015. Manual de fonética acústica experimental: aplicação a dados do português. São Paulo: Cortez Editora.

BERMÚDEZ-OTERO, Ricardo. 2006. Morphological structure and phonological domains in Spanish denominal derivation. In.: MARTÍNEZ-GIL, Fernando; COLINA, Sonia (Eds.) Optimality-theoretic studies in Spanish phonology, 278-311. Amsterdam: John Benjamins.

BERMÚDEZ-OTERO, Ricardo. 2013. The Spanish lexicon stores stems with theme vowels, not roots with inflectional class features. Probus, v. 25 (1), p. 3-103.

BISOL, Leda. 1992. O acento e o pé métrico binário. Caderno de Estudos Linguísticos, v. 22, p. 68-80. Campinas.

BISOL, Leda. 2010. O diminutivo e suas demandas. Revista Delta, v. 26, n.1. São Paulo. Disponível em: http://revistas.pucsp.br/index.php/delta/article/ view/19967 (acesso em 7/5/15).

BISOL, Leda. 2011. O diminutivo e suas demandas, uma versão revisitada. Revista Virtual de Estudos da Linguagem - ReVEL, edição especial n. 5.

BOERSMA, Paul; WEENINK, David. 2005. Praat: doing phonetics by computer. Versão 5.3.84. Disponível em: www.praat.org.

BROD, Lilian Minikel; SEARA, Izabel Christine. 2013. As vogais orais do português brasileiro na fala infantil e adulta: uma análise comparativa. Linguagem \& Ensino, v.16, n.1, p. 111-130, Pelotas, jan./jun.

CÂMARA JR., Joaquim Mattoso. 2014 [1975]. História e estrutura da língua portuguesa. Rio de Janeiro: Padrão.

CANTONI, Maria Mendes 2013. O acento no português brasileiro: uma abordagem experimental. Tese de Doutorado. Universidade Federal de Minas Gerais.

CORBIN, Danielle. 1987. Morphologie dérivationnelle et structuration du lexique. Tubinga: Max Niemeyer Verlag.

ELORDIETA, Gorka. The Word in phonology. In.: IBARRETXE-ANTUÑANO, Iraide; MENDÍVIL-GIRÓ, José-Luis. 2014. To be or not to be a word: new reflections on the definition of word. Cambridge Scholars Publishing. p. 6-65.

HARRIS, James. 1983. Syllable structure and stress in Spanish: a nonlinear analysis. Cambridge: MIT.

LADEFOGED, Peter. 2005. Phonetic data analysis: an introduction to fieldwork and instrumental techniques. Blackwell Publishing.

LEE, Seung-Hwa. 1995. Morfologia e fonologia lexical do Português do Brasil. Tese de Doutorado. Unicamp - IEL: Campinas.

MASSINI, Gladis. 1991. A duração no estudo do acento e ritmo do português. Dissertação de Mestrado - Universidade Estadual de Campinas, Campinas. 
MATZENAUER, Carmen Lúcia Barreto; BISOL, Leda. 2016. O inventário e a distribuição subjacente das vogais temáticas na classe dos nomes do português. Alfa, São Paulo, 60 (2): 341-353.

MORAES, João. 1998. Intonation in Brazilian Portuguese. In: HIRST, Daniel; DI CRISTO, Albert (orgs.) Intonation System. A Survey of Twenty Languages. Cambridge: Cambridge University Press, p. 179-193.

NESPOR, Marina; VOGEL, Irene. 1986. Prosodic Phonology. Dordrecht: Foris Publications.

PEPPERKAMP, Sharon. 1997. Prosodic words. HIL dissertation 34. The Hague: Holland Academic Graphics.

RIO-TORTO, Graça. 2000. Configurações sufixais e z-sufixais em português. Revista Portuguesa de Filologia, volume XXIII. Coimbra.

SCALISE, Sergio. 1984. Generative morphology. Dodrecht: Foris.

SCHWINDT, Luiz Carlos. 2000. O prefixo no Português Brasileiro: análise morfofonológica. Tese de doutorado. Porto Alegre, Pontifícia Universidade Católica do Rio Grande do Sul.

SCHWINDT, Luiz. Carlos. 2008. Revisitando o estatuto prosódico e morfológico de palavras prefixadas do PB em uma perspectiva de restrições. Alfa (ILCSE/ UNESP), v. 52(2), p. 391-404.

SCHWINDT, Luiz. Carlos. 2013a. Neutralização da vogal pretônica e formação de palavras em português brasileiro. Organon, v. 28, p. 1-19.

SCHWINDT, Luiz. Carlos. 2013b. Palavra fonológica e derivação em português brasileiro: considerações para a arquitetura da gramática. In: BISOL, Leda; COLLISCHONN, Gisela (Org.) Fonologia: teorias e perspectivas. $1^{\text {a }}$ ed. Porto Alegre: EDIPUCRS, p. 15-28.

SCHWINDT, Luiz Carlos. 2014. Prosodic Word and Morphological Derivation in Brazilian Portuguese. Supplemental Proceedings Phonology 2013 (extended abstract). Linguistic Society of America. 2014.

SELKIRK, Elisabeth. 1982. The syntax of words. Cambridge, Massachussetts: MIT Press. 1982.

TRUBETZKOY, Nikolai. [1939] 1969. Principles of phonology. Translated by Christiane Baltaxe from Grundzüge der Phonologie. Berkeley: University of California Press.

ULRICH, Camila Witt. 2013. Consciência sobre palavridade em português brasileiro. Trabalho de Conclusão de Curso. Universidade Federal do Rio Grande do Sul. Porto Alegre.

ULRICH, Camila Witt; SCHWINDT, Luiz Carlos. 2012. O locus morfológico e prosódico da afixação por -inho e -zinho em português brasileiro. Comunicação oral no XXIV Salão de Iniciação Científica da Universidade Federal do Rio Grande do Sul.

VIGÁRIO, Marina. 2003. The prosodic word in European Portuguese. Berlin: Mouton de Gruyter.

VILLALVA, Alina. 1992. Portuguese compounds. Rivista di Linguistica, v. 4.1, p. 201-219. 